\title{
A Case Study in Interactive Narrative Design
}

\author{
Carol Strohecker \\ Published in Designing Interactive Systems: Processes, Practices, Methods, and Techniques, \\ Association for Computing Machinery, 1997, pp. 377-380. \\ Originally appeared as Working Paper 97-03, Mitsubishi Electric Research Laboratories.
}

\begin{abstract}
The paper describes lessons learned about the design of a form for interactive narrative. The lessons are based on an initial prototype and have ramifications for both a next-step implementation and for broader understanding of the form. Key lessons pertain to pacing, narrative structure, giving feedback through the interface, and contexts for use.
\end{abstract}




\section{INTRODUCTION}

There is a growing tradition of experiments with "interactive narrative." Researchers, media producers, and artists grapple with problems of continuity, granularity, and authorship that arise as people use computational media to generate and present stories. Recent experiments emphasize way-finding and role-playing. Rooted in the text-based games of the early 1980's [1], MUDs and MOOs ${ }^{1}$ allow players to create characters and extend the virtual environment [7]. Often, algorithms control the story presentation or automate objects and characters as "agents" $[1,2,3,7]$. Players interact by building and socializing, often generating narratives that become part of the culture of the virtual domain.

At another extreme are experiments that model interactivity as plot-branching. A typical strategy is to develop a story with several possible endings and ask audience members to choose one. Both audiences and producers have found this approach dissatisfying. Directors find costs associated with the complex production to be prohibitive, and CDROM users and theater-goers often feel they are missing something if they can't see all the possible endings. Furthermore, many people think an artist, director, or creator should be the one to decide how a story ends.

Similar dilemmas arise with any fragmentation of plot. Plot and character are essential narrative elements. We want to develop them, not fragment or destroy them.

An early experiment structured interactivity as a form of character development [4]. A Different Train of Thought had a specific plot: the story began in a certain way, proceeded in a certain way, and ended in a certain way. However, different characters saw and interpreted events in different ways. Viewers ${ }^{2}$ interacted by accessing characters' thoughts. The "thought-images" added importantly to portrayals of the characters.

The experiment described here, Tired of Giving In (TOGI), also maintains a particular storyline and structures interaction through character development. TOGI recounts events leading to the Montgomery Bus Boycott, a key moment in the American Civil Rights Movement. Viewers learn about the events through "characters" and "chorus members" who tell the story. The characters are figures such as the city mayor and leaders of the local NAACP. ${ }^{3}$ They reveal roles, attitudes, and events as they speak with one another. Chorus members may speak to each other, to the characters, or to the viewers. Following the model of the chorus in ancient Greek theater, chorus members fill in gaps in the narrative and add perspective through commentary [5]. In the purest interpretation of the model, TOGI viewers interact through the chorus. We broadened this interpretation so that viewers can query characters as well as chorus members.

\footnotetext{
${ }^{1}$ MUD stands for "MultiUser Dungeon" (or Domain or Dimension); MOO means "MUD Object-Oriented" (a reference to the style of the associated programming language).

2 "Viewer" is an unfortunately passive term for one who is looking, listening, taking actions, and constructing meaning through the course of a program. "Participant" and "interactor" have preferable connotations but tend to become unwieldy; "player" suggests the context of a game.

${ }^{3}$ NAACP stands for "National Association for the Advancement of Colored People."
} 


\section{BASIC DESIGN PROBLEM}

We formulated a structure that would present the basic story and allow the viewer to unfold further detail by interacting. TOGI proceeds through four scenes: ${ }^{4}$ the town of Montgomery, Alabama; the public bus on which Rosa Parks is arrested; the jail cell to which she is taken; and the church in which community members congregate.
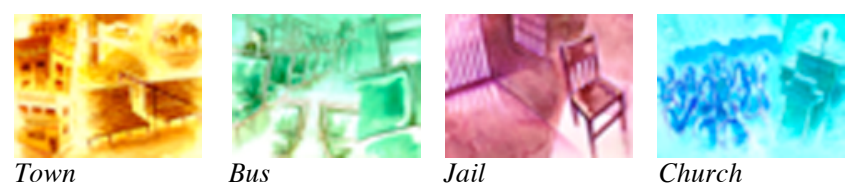

As in ancient Greek plays, the scenes alternate with choral refrains.

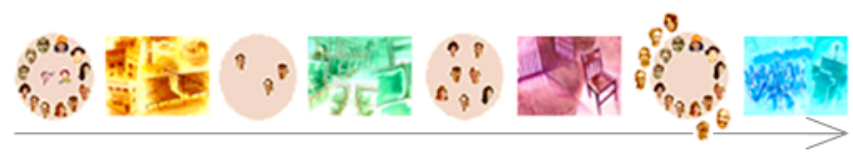

The program opens as the chorus members introduce themselves and their varying perspectives. Members of chorus past are African slaves: one is proud, another mourns, another resigns himself to capture. Members of chorus present struggle with the 1955 events: two favor segregation, two favor desegregation, and two waver. Members of chorus future are urban young people of the 1990s who question how the events affect them: one is optimistic, another is pessimistic, and another is apathetic.

The story begins in a typical town in the American South of the 1950s. A chorus member describes the setting and racial segregation as a way of life. Then, in a refrain, chorus members chant about people's senses of resignation and inferiority. In the next scene, the chorus leader tells of Rosa Park's refusal to give her bus seat to a white man. Chorus members in the next refrain chant about injustices and absolutes in civic law. The chorus leader then speaks of the fear and uncertainty of being in jail. The next refrain combines chants with narrative about organizing a bus boycott for the day of the Parks trial. Finally the leader describes the jubilant scene in the church as people celebrate the boycott's success and vote to continue it.

If the viewer doesn't interact, the chorus leader says her part and the program proceeds automatically to the next refrain. However, before leaving a scene, the viewer may want to engage more of the story. When the viewer activates part of a scene, it reveals certain characters and chorus members.

\footnotetext{
${ }^{4}$ Illustrations are by Steven Alexander.
} 


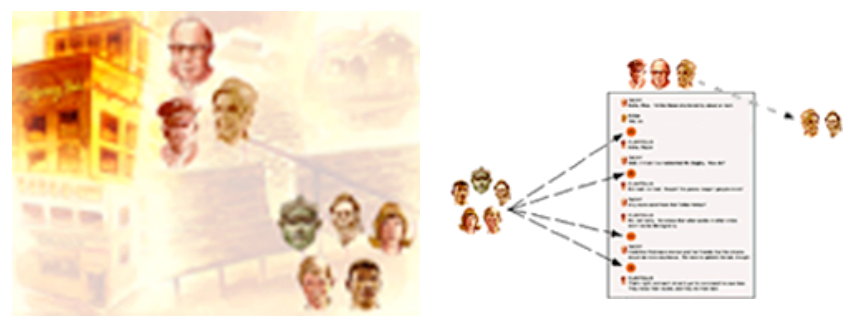

The characters begin conversing. As they speak, the viewer can activate chorus members. Those activated wait for an opportune moment and intersperse comments within the characters' dialog. Similarly, if the viewer clicks on a character, he or she exchanges remarks with a program-selected chorus member. Then the dialog continues. We wrote the script so that interspersed comments correspond to specific points of the characters' dialog.

The basic design problem is in using the interface to communicate the narrative structure, possibilities for interaction, and different states of the characters...

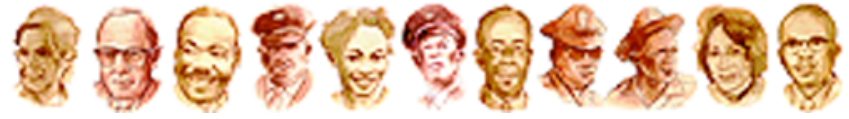

...and chorus members.

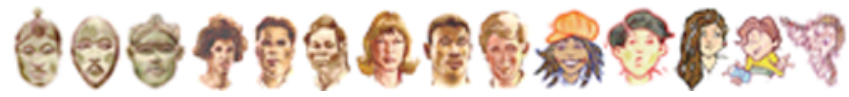

\section{CONSTRAINTS}

Our aim was to develop a research prototype of an educational application. Nevertheless, in deference to copyright, budget, and schedule, we minimized the use of archival photographs and movie footage. We relied mainly on original drawings, photos, and videos.

Given that so much of the flow and interface cues depend on states of the scenes and characters, we decided that a flexible object-oriented programming environment would best enable implementation of this prototypical structure. Unfortunately the accompanying media tools were still being developed; we became a beta site and eventually omitted much of the sound and video we had planned to use. Illustrations, still photos, and narration carry most of the presentation in this initial implementation.

\section{ORGANIZATIONAL SETTING}

We developed TOGI in meeting rooms and offices of a research lab. The lab is designed for software production but not necessarily media production, so we improvised when it came to audio recording, etc. As the project grew we used computers at several different locations and relied on network communications to exchange files (which by the end of the production effort numbered in the thousands). 
So far the everyday lab setting is the site for informal usability tests. Interested people simply try out the prototype in the offices where we developed it. In addition to their feedback, the exercise of implementation taught us many important lessons.

\section{LESSONS LEARNED}

The lessons pertain to each phase of the project: conceptualization, design, production, and viewing context.

\section{Even pacing}

Computer-based narratives may be rooted in games, but there are distinct differences in purpose and presentation. One difference is in pacing, which is likely to be slower for narratives. Variation in timing can add interest, but if the pace varies too much, viewers can become disconcerted. Several factors contributed to TOGI's overall rhythm.

The program should be interactive throughout.

We emphasized the alternation between scenes and refrains by casting it in terms of interaction: viewers can interact with the scenes but not the refrains. Unfortunately this treatment becomes confusing, partly because the chorus members look much the same in both arenas. While it is appropriate to devote the refrains to the chorus, we needn't have excluded participation by the viewer; on the contrary, the viewer-as-chorus model could be well served by bringing viewers into the refrains.

\section{Use "chunks" of comparable length.}

The non-interactivity is most problematic in the final refrain. All of the refrains amplify characters' feelings and effects of events, but the final refrain also furthers the plot. This refrain is therefore significantly longer than the others. The contrast becomes unsettling, and the duration is simply too long for people to watch without interacting.

The story is told mainly through audio as characters and chorus members narrate and converse. A reasonable listening "chunk" corresponds to a line or two of script. Longer spoken parts would work best if the viewer had greater control over the presentation and could stop them.

The number of interactive modules in a scene can affect the program's overall pace. Many viewers like to explore each module; therefore keeping the number more or less constant can help the story progress evenly. Sequences of still images appear as the modules and character dialogs unfold. We found that these play-outs worked best at a brisk pace, preferably complementing the rhythm of the voices. Moving images work best as brief clips.

\section{Underlying structure}

We were so determined to keep the basic story intact that we provided primarily for oneway movement through the narrative. The viewer has to go through the scenes in 
sequence: first Town, then Bus, then Jail, then Church. (Rosa Parks must be arrested before the boycott begins.) However, there is some leeway within each scene: the viewer can visit the interactive modules in any order.

This compromise works well for Town and Church, but questionably well for Bus and Jail. In Bus, it's possible for Parks to be arrested before the driver asks her to give up her seat. In Jail, it's possible for her to be bailed out before she is fingerprinted. Fortunately the chorus leader's narration of the main story provides a chronological framework that enables viewers to construct a proper sense of events.

Allow users to navigate freely.

We needn't have maintained the overall directionality so rigidly. Most viewers want to return to an earlier point in order to review or interact differently. Their comments suggest that the underlying narrative structure supports continuity despite viewers' variable access to story details.

\section{Feedback through the interface}

Each interactive module includes specific characters and chorus members. The relevant characters are always active, but only some of the relevant chorus members become available to offer comments. The program determines which chorus members are available, depending on how the user has interacted up to that point. If a viewer consistently chooses a pro-boycott chorus member, for example, the program may make an anti-boycott person available in the next unfolding. In this way, the algorithm strives to balance the presentation through access to different perspectives on the story.

As the viewer interacts, the faces change to indicate what the chorus members are doing:
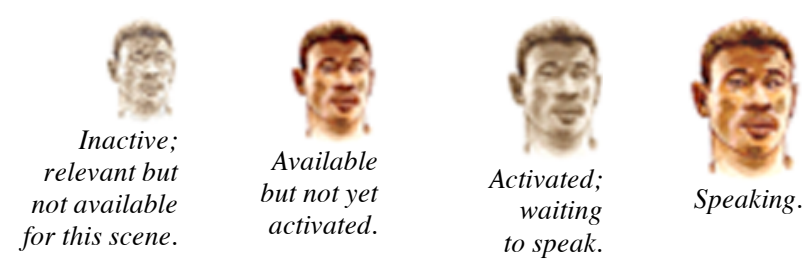

Notice that only one of these states ("available") indicates that the viewer can click on the chorus member to affect a response. Unfortunately viewers tend to try clicking on all the versions. The images resemble each other too closely, and it takes a while for viewers to realize that a given picture is just one of the set. Furthermore, we need to rethink inclusion of the "inactive" version. By the time it appears, there is nothing the viewer can do to make that chorus member "available." The deeper problem is in communicating that interactions have a long-term effect.

Use multiple cues.

Dynamic full-figure portrayals of characters and chorus members could provide a greater range for communicating changes of state. However, the static faces do allow a certain economy of representation, and they could work better as a system of signals. Tufte 
describes the technique of "small multiples," which help to establish a context by showing variations on a pictorial theme [7]. We could use this technique to show all the choral states simultaneously, with a visual distinguisher such as highlighting or enlargement to indicate state changes.

In addition to visual differentiation, an audio response could strengthen the feedback when a viewer interacts. We recorded utterances such as "uh-huh," "amen," "okay," etc., but had to stop production before incorporating them. They should be part of a later experiment.

\section{Viewing context}

People have a lot to say when they spend time with TOGI, both about the complexity of the program and the significance of the story. Discussion is an important part of the viewing experience. This need, combined with the model of the chorus collective, suggest that a MUD-like environment could be an interesting milieu. We hope to develop the next version on a multiuser platform.

\section{ACKNOWLEDGMENTS}

Carol Strohecker developed TOGI in collaboration with Kevin M. Brooks of the MIT Media Lab. Larry Friedlander of Stanford University contributed importantly to initial conceptualizations. Steven Alexander, Shana Priwer, and Brad Marshall were invaluable members of the production team; dozens of others contributed their voices and skills. We are grateful to Glorianna Davenport and the Interactive Cinema Group of the MIT Media Lab for providing equipment and space during some cycles of software development. TOGI has been described at the General Assembly on Multimedia Writing (Paris, fall 1995) [5] and the ACM Multimedia conference (Boston, fall 1996) [2]. The prototype has been demonstrated at Liverpool John Moore University's MediaActive conference (spring 1996) and at the Prix Möbius conference (Paris, fall 1996), sponsored by UNESCO and the European Commission. The work is supported by MERL - A Mitsubishi Electric Research Laboratory, in Cambridge, Massachusetts, USA.

\section{REFERENCES}

1. Bates, Joseph. The role of emotion in believable agents. Communications of ACM, 37(7): 122125, 1994.

2. Brooks, Kevin. Do agents use rocking chairs? Proceedings of ACM Multimedia, Boston, 1996. 3. Laurel, Brenda. Interface agents: Metaphors with character. The art of human-computer interface design. ed. Brenda Laurel. Addison-Wesley, Reading, MA, 1990.

4. Strohecker, Carol. The videodisc and interactive narrative. Master's thesis, Massachusetts Institute of Technology, 1986.

5. Strohecker, Carol. Tired of giving in: Experimenting with the Greek chorus as a model for interaction with stories. Nov'Art: Les états généraux de l'écriture multimedia. ART3000, Paris, 1996.

6. Tufte, Edward. Envisioning information. Graphics Press, Cheshire, CT, 1990.

7. Turkle, Sherry. Life on the screen. Simon and Schuster, New York, 1995. 